\title{
Erratum to: Sedentary time in adults and the association with diabetes, cardiovascular disease and death: systematic review and meta-analysis
}

\author{
E. G. Wilmot • C. L. Edwardson • F. A. Achana • \\ M. J. Davies • T. Gorely • L. J. Gray • K. Khunti • \\ T. Yates $\cdot$ S. J. H. Biddle
}

Published online: 31 January 2013

(C) Springer-Verlag Berlin Heidelberg 2013

\section{Erratum to: Diabetologia \\ DOI 10.1007/s00125-012-2677-z}

Although this meta-analysis included prospective cardiovascular mortality and all-cause mortality data from the EPIC Norfolk study by Wijndaele et al [36], the recently published non-fatal cardiovascular disease data from the same cohort (Wijndaele et al [30]) were not included. The authors regret this oversight and have now incorporated these data into their meta-analysis. As a result, the RR of CVD has changed from 2.47 (95\% CI 1.44, 4.24) to 2.02 (1.42, 2.89) (see amended Fig. 2). The quality score assigned to the Wijndaele paper [30], which was originally calculated based on the cross-sectional diabetes data from this publication, increases from 0 to the maximum 6 in table 1 . The inclusion of the CVD data from Wijndaele [30] does not alter the main conclusions of the paper.

The online version of the original article can be found at http://dx.doi.org/ 10.1007/s00125-012-2677-z.

E. G. Wilmot $\cdot$ M. J. Davies $\cdot$ T. Yates $(\bowtie)$

Department of Cardiovascular Sciences, University of Leicester,

Leicester Diabetes Centre, Leicester General Hospital,

Gwendolen Road,

Leicester LE5 4PW, UK

e-mail: ty20@1eicester.ac.uk

E. G. Wilmot • C. L. Edwardson • M. J. Davies • K. Khunti

Leicester Diabetes Centre, Leicester General Hospital,

University Hospitals of Leicester,

Leicester, UK

C. L. Edwardson · T. Gorely · S. J. H. Biddle

School of Sport, Exercise and Health Sciences, Loughborough University,

Loughborough, UK

F. A. Achana $\cdot$ L. J. Gray $\cdot$ K. Khunti

Department of Health Sciences, University of Leicester, Leicester Diabetes Centre, Leicester General Hospital,

Leicester, UK

M. J. Davies $\cdot$ K. Khunti $\cdot$ T. Yates $\cdot$ S. J. H. Biddle

NIHR Leicester-Loughborough Diet,

Lifestyle and Physical Activity Biomedical Research Unit,

Leicester, UK 
Fig. 2 The association between sedentary time and health outcomes, adjusted for baseline event rate. The reference group is the lowest sedentary time group. HR and RR greater than 1 suggests that high sedentary time is harmful. Solid lines indicate estimated HR/RR with $95 \% \mathrm{CI}$; dotted lines indicate 'shrunken' studyspecific estimates with $95 \%$ CrI. Diamonds indicate pooled and predictive $\mathrm{HR} / \mathrm{RR}$ with associated $95 \% \mathrm{CI} / \mathrm{CrI}$.

Cardiovascular disease was not adjusted for baseline event rate due to the small number of studies for this outcome, hence no predictive effect and interval

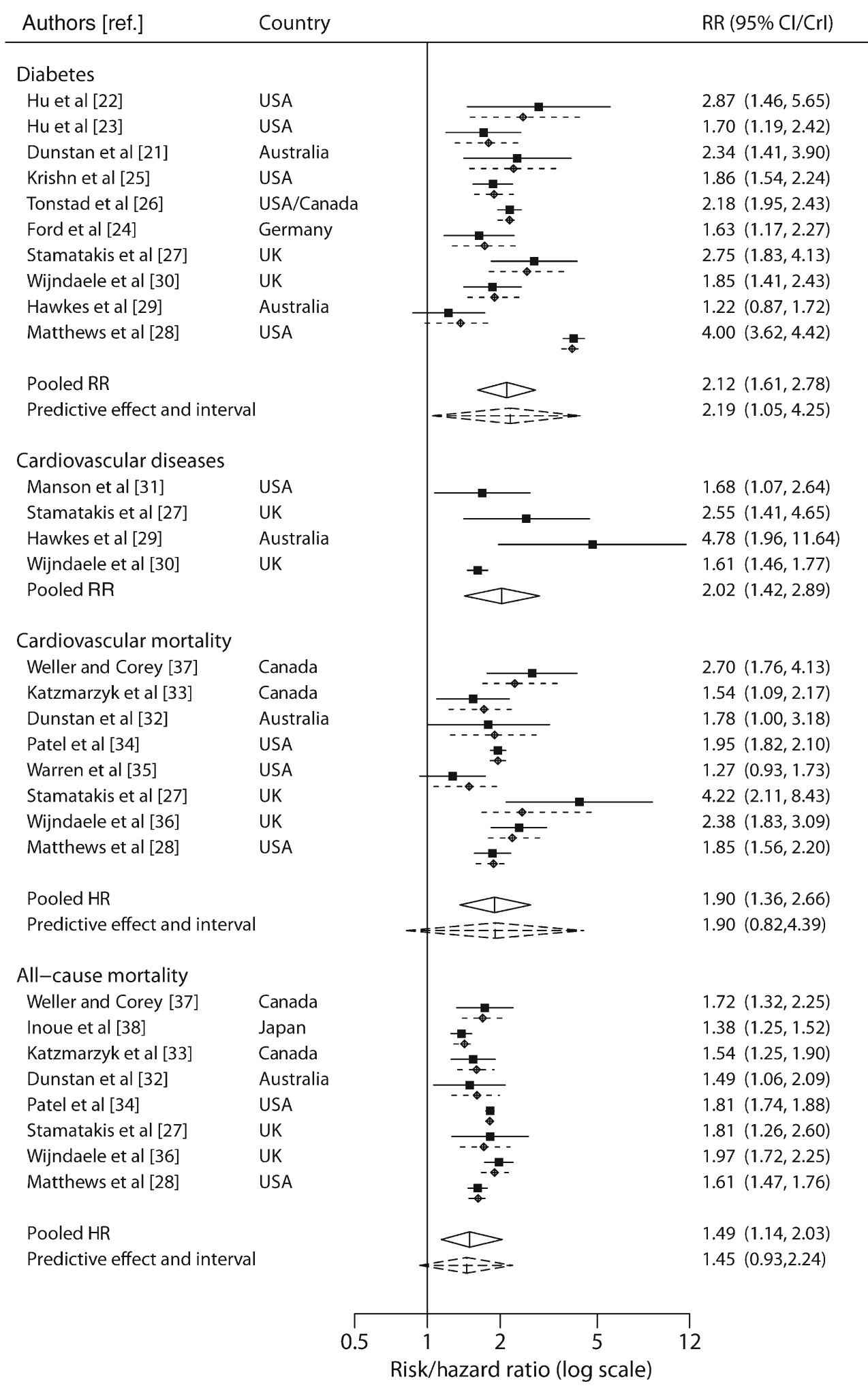

